\title{
Presenting the Structural Equation Modeling of Achievement Goal and Self-regulation on Passing the Course
}

\author{
Somaye Davoodi ${ }^{1,}$, Kazem Khaefi ${ }^{2}$, Firooz Sadighi ${ }^{3}$ \\ ${ }^{1} \mathrm{PhD}$ candidate, Islamic Azad University, Shiraz Branch \\ ${ }^{2}$ University instructor, Payamnoor University, Darab Branch \\ ${ }^{3}$ Islamic Azad University, Shiraz branch \\ *Corresponding author: davodi.2011@gmail.com
}

\begin{abstract}
The aim of this research was to investigate the relationship between goal orientation and academic achievement with emphasizing the mediating role of self-regulation of the students. The research method was correlational and the statistical population included all BA students of Islamic Azad University who choose general English in 2015-16 academic year (2 semesters) at Shiraz. They were selected through random sampling. The research tools were standard goal orientation and self- regulation questionnaires. The data were analyzed through structural equation modeling. The results of the structural equation modeling revealed that there was a direct and meaningful relationship between goal orientation and self- regulation with academic achievement. Moreover, the results indicated that the direct effect of academic achievement on self -regulation was meaningful.
\end{abstract}

Keywords: structural equation modeling, achievement goal, self-regulation, academic achievement, Islamic Azad University

Cite This Article: Somaye Davoodi, Kazem Khaefi, and Firooz Sadighi, "Presenting the Structural Equation Modeling of Achievement Goal and Self-regulation on Passing the Course." American Journal of Educational Research, vol. 5, no. 6 (2017): 629-632. doi: 10.12691/education-5-6-6.

\section{Introduction}

Our higher education system produced undergraduates who had just memorized some syllabuses which to some extent were not useful in real life. Such undergraduates did not keep abreast of current developments and technologies. Achievement goal theory was one of the most prominent and useful frameworks in understanding motivation and was used in general education and skill areas [12]. The theory proposed an integrated model including some beliefs which lead to different ways of responding to achievement situations [1]. The theory also emphasized that goal -oriented persons act better than goal-less individuals and persons with challenging goals engaged in activities better than the persons with easy goals. Dwect and Leggett, Ames and Archer believed that achievement goals referred to the reasons students have on educational duties and assignments. They also eager to know why people pursue goals and what kind of cognitive and environmental features affect them and what impacts they have on their cognitive, affective and behavioral outcomes. Elliots and Church [4] presented a multidimentional framework of mastery goals, performance goals and avoidance goals (cited in [9]). According to them, the students with performance goals have appropriate judgments and also power of concentration on their assignments (Cited in [17]). Whereas those with avoidance goals are lacking in these characteristics. Finally those with mastery goals have tended to emphasize developing skills and self-learning [7]. Mohsenpoor, et al [15] investigated the relationship between achievement goals and academic achievement. The results revealed that the three above mentioned goals have direct impact on students' academic and achievement in math, and also there was a negative relationship between avoidance goals and achievement. Moreover, the results of Elliot and Church [4] showed that there was a direct and positive correlation between achievement goals and academic achievement. Delavarpur (2005) in his research "'predicting metacognition awareness and academic goal orientation", studied the role of metacognition awareness and academic goals orientation. (mastery goals, performance goals and avoidance goals) on achievement. The results showed that mastery goals and performance goals were direct and meaningful predictors of academic achievement and avoidance goals were negative predictor of academic achievement. Furthermore, Khademi and Noshadi [13] in their research "study the relationship between goal orientation and self-regulated learning on academic achievement" revealed that goal orientation and self -regulated learning are direct and meaningful predictors of academic achievement. Whereas goal avoidance was negative and meaningful predictor of academic achievement. Also the negative relationship between goal avoidance and academic achievement has been confirmed in Elliot and Mcgregor [6], Church et al (2001) and Elliot and Church [4] studies. 
Self-regulation was a terms used by different theorists in recent years. Self-regulation occurred when learners used individualistic process to regulate their behavior purposefully and try to preserve or change the learning environment $[18,20]$. According to Zimmerman (2008) self-regulation is the self -directive process through which learners transform their mental abilities into academic skills. Self-regulated learning environment is one of the most important sources of learning. Therefore, every learner can teach themselves self-regulated strategy. Mcmahon and Oliver [14] considered a learner as the main character of a story who was searching for new knowledge and striving to have a perfect command of it. Self -regulation emphasized how one can choose, organize, create or preserve their own learning environment and how they can manage time and instruction [21]. Amini [3] in his research indicated that there was a meaningful relationship between selfregulated strategies and academic achievement. In this study a regression model was used to determine the portion of every predictive variable. The results of regression analysis revealed that 0.119 from academic achievement variance was determined by self-regulation variable. Stipec and Gralinski [19] stated that the students with mastery goals used meta cognition and self-regulated strategies to obtain their goals and to do their assignments. Therefore their educational performance would improve. However, the students with performance goals used low cognitive strategies such as rehearsal and so their educational performance would be poor. Jokar (2005) in his research "studying the relationship between goal orientation and self-regulation among shiraz university students", investigated kinds of goal orientation and different aspects of self-regulation including meta cognition, cognition and motivation. In this paper, standard regression showed that mastery goal predicted meta cognition and cognitive aspects positively but it predicted motivation negatively. Also he found that performance goal had only predictive role in motivation aspect but avoidance goal had the negative role of prediction in all aspects. Our present study is different from others since it tries to present a structural equation modeling of achievement goal and self-regulation on passing the course.

\section{Methods}

Research method of this study was correlation and 410 students of Shiraz Islamic Azad University were selected by stratified sampling. Measurement tool in this research were standardized questionnaires. Self-regulation questionnaire (Bandy, \& Moore, 2010) with 13 items was scaled by 5-point, Likert-type and achievement goal (Midgley et al, 1993) was quantified by using a 5-point, Likert-type scale ranging from never true to always true. The measures of the study presented in appendix part. In this study, to evaluate the reliability of questionnaires Cronbach`s Alpha was used which indicated in Table 1.

Table 1. Reliability Coefficients of Variables

\begin{tabular}{cc}
\hline Variables & Cronbach Alpha \\
\hline self-regulation & 0.76 \\
achievement goal & 0.82 \\
\hline
\end{tabular}

Also, final and mid- term grade were used as the measurement tool for students`academic achievement.

\section{Results}

To analyze the collected data, the researcher used SPSS and AMOS software. Because the researchers found rich and complete literature about the relationship between the variables of the study, they decided to use structural equation modeling as the method in statistical analysis. It must be noted that this statistical method needs definite literature. Since the purpose of study was investigating the constructive relationship between variables via structural equation modeling, therefore, standard direct effect and significance level were presented in Table 2.

Table 2. Standard direct effect, $T$ value and significance

\begin{tabular}{|c|c|c|c|}
\hline \multicolumn{3}{|c|}{ Estimates } & \multirow{2}{*}{ Significance } \\
\hline Variables & Standard direct effect & T value & \\
\hline \multicolumn{4}{|c|}{ Direct effect of achievement goal on: } \\
\hline Self-Regulation & 0.764 & 5.628 & 0.01 \\
\hline Academic Achievement & 0.351 & 2.621 & 0.05 \\
\hline \multicolumn{4}{|c|}{ Direct effect of Achievement Goal on: } \\
\hline performance Goals & 0.803 & 6.838 & 0.01 \\
\hline Avoidance Goal & 0.734 & 5.522 & 0.01 \\
\hline \multicolumn{4}{|c|}{ Direct effect of Self-Regulation on: } \\
\hline Meta Cognitive & 0.511 & 3.433 & 0.01 \\
\hline Cognitive & 0.602 & 4.106 & 0.01 \\
\hline \multicolumn{4}{|c|}{ Direct effect of Academic Achievement on: } \\
\hline Midterm & 0.558 & 3.832 & 0.01 \\
\hline Final & 0.683 & 4.658 & 0.01 \\
\hline
\end{tabular}




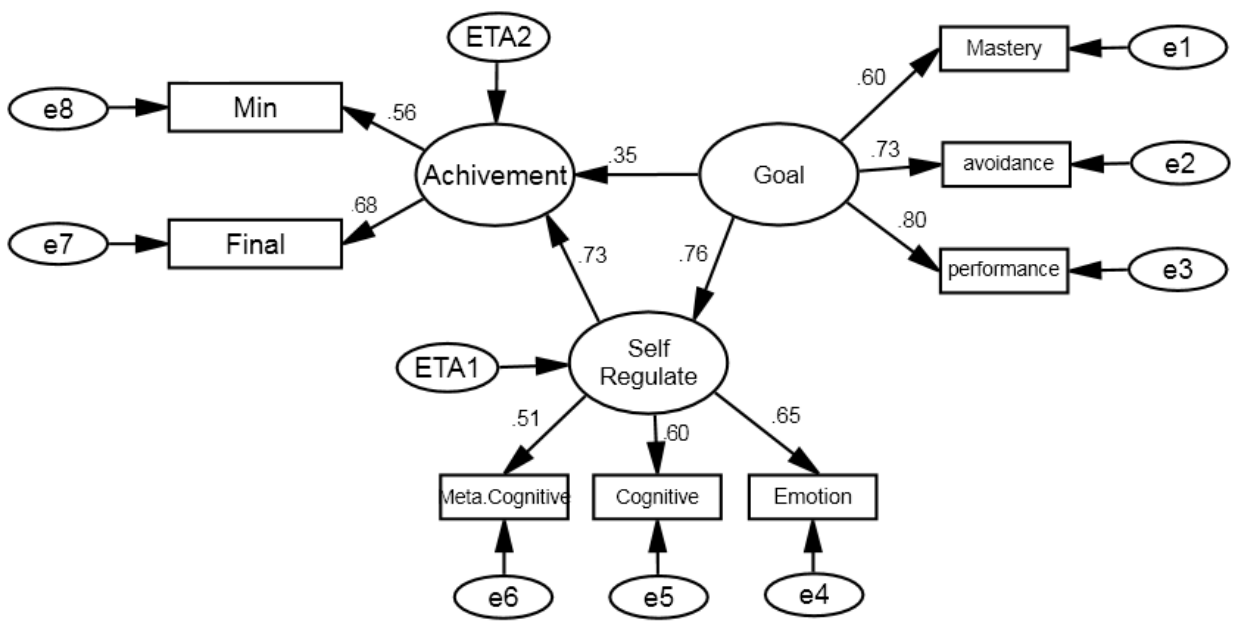

Figure 1. Academic achievement structural equitation modeling

The results of the Table 2 revealed that there was a direct and meaningful relationship between goal orientation (0.351) and self-regulation (0.732) with academic achievement $(\mathrm{p}=0.01)$. Also the effect of goal orientation on mastery goals (0.600), performance goals (0.803) and avoidance goals (0.734) was meaningful and finally the effect of self-regulation on cognitive (0.602), meta cognitive (0.511) and motivation (0.650) was meaningful. It should be noted that explained total variance of academic achievement was equal to 0.27.

Adjusted Goodness of Fit Index(AGFI)(0.976), Goodness of Fit Index(GFI)(0.983), Comparative Fit Index(CFI) (0.989) and Normed-fit index (NFI)(0/960) are larger than 0.90 and Root Mean Square Residual (RMSR)(0.032) was smaller than 0.05 and on the other hand Chi-Square, Degree of Freedom and $x^{2} / d f$ statistic was meaningful. The first model of the research which had been done through the literature review, took a good fitness with the data.

\section{Discussion}

The aim of this study was to investigate the relationship between achievement goals and self-regulation with academic achievement in Islamic Azad University students at Shiraz. Therefore, with the combination of achievement goals and self-regulation theories, the researcher investigated the related factors with academic achievement by structural equation modeling. The results of structural equation modeling showed that achievement goal was one of the major factors affecting academic achievement. This result was confirmed in the literature by Elliot and Church, [4]; Elliot and Mac Gregory, [4,5]; Elliot and Mac Gregory, [5]; Harackiewicz et al [8], Joker and Delaware Poor, [11].

If the students take achievement goals in particular functional goals in their learning processes, the progress would be higher and they would acquire many successes in their learning. The results showed that self-regulation significantly predict academic achievement, and had significant effect on it. It meant that Self-regulation was one of the most important factors affecting academic achievement, according to the findings of Amini, [3]. These results suggested that to the extent that students used self-regulation strategies in learning, they had more progress in academic achievement.

This would cause learning to be successful. The results also showed that among the components of achievement goals, self-regulation was the more powerful predicator of performance goal.. Also, achievement goals predicted self-regulation of students directly and significantly and affect it. This finding was in accordance with the results of Ames and Archer, [2]; Dweck and Leggett, 1988. This meant that in performance goal orientation, students try to compare performance with other students and try to demonstrate his competence and, avoid challenging tasks and less inclined to self-regulation activities. Avoidance goal was also one of the components of goal orientation and self-regulation was one of the factors affecting students' performance. In regard the negative relationship between self-regulation and avoidance goals, results were in line with studies of Ames and Archer, [2]; Dweck \& Leggett, 1988; Ames, [1]. It meant that the more the orientation of the students is focused on avoiding goal, the less the cognitive and metacognitive strategies used.

Therefore, according to the findings of the research and the importance of self-regulation and academic achievement, it is recommended that the content of syllabuses should be planned due to students orientation and learners educational content. Moreover, the syllabuses should be based on challenging assignments that all students could achieve success in them, and could gain motivation. It could be concluded that attending the workshops and familiarizing with self-regulation learning and acquiring knowledge of it is useful. Although learning is a complicated process and many other psychological factors like preparedness, interest, attitude, aptitude, mental health, natural ability to learn, and individual differences affect it, but because some limitation in time and money, the researchers decided to eliminate other factors and only focus on different dimensions of goal orientation on achievement goal. But the role of other factors on achievement must not be neglected.

\section{References}

[1] Ames, C. (1992). Classrooms: Goals, structures, and student motivation. Journal of Educational Psychology, 84, 261-271. 
[2] Ames, C., \& Archer, J. (1988). Achievement goals in the classroom: Students' learning strategies and motivation processes. Journal of Educational Psychology, 80, 260-267.

[3] Amini, Sh. (2003). The role of self-efficacy, self-regulation and self-esteem in academic achievement in high school.MA Thesis, teacher training university.

[4] Elliot, A. J., \& Church, M. A. (1997). A hierarchical model of approach and avoidance achievement motivation. Journal of Personality and Social Psychology, 72, 218-232.

[5] Elliot, A. J., \& McGregor, H. (2001). A 2 _ 2 achievement goal framework. Journal of Personality and Social Psychology, 80, 501-519.

[6] Elliot, A. J., McGregor, H., \& Gable, S. (1999). Achievement goals, study strategies, and exam performance: A mediational analysis. Journal of Experimental Social Psychology, 91, 549-563.

[7] Gonida, E. N., Voulala, k., \& kiosseoglou, G. (2009). Students' achievement goal orientations and their behavioral and emotional engagement: Co-examining the role of perceived school goal structures and parent goals during adolescence. Learning and Individual Differences, 19, 53-60.

[8] Harackiewicz, J. M., Barron, K. E., Tauer, J. M., Carter, S. M., \& Elliot, A. J. (2000). Short-term and long-term consequences of achievement goals: Predicting interest and performance over time. Journal of Educational Psychology, 92, 316-330.

[9] Jahromi, R, Lavasani M, Rastegar, A, Mooghali A. (2010). Presenting a model of predicting computer anxiety in terms of epistemological beliefs and achievement goals, 26, 602-608.

[10] Jocar B. (2005). The relationship between goal orientation and self-regulation in student of different fields at Shiraz University. Journal of Social Sciences and Humanities of Shiraz University; 22(4): 56-71.

[11] Joker, B, Delaware Poor, M. (2007). The relationship of procrastination educational with achievement goals. Journal of new thoughts in education.3, $(3,4)$.
[12] Kaplan, A., \& Flum, H. (2010). Achievement goal orientations and identity formation styles. Educational Research Review 5, 50-67.

[13] Khademi, M. Noshadi, N. (2006). Relationship between goal orientation with selfregulation and academic achievement in students of Shiraz University. Journal of Humanities and social sciences, 25(4).

[14] McMahon, M., \& Oliver, R. (2001). Promoting self-regulated learning in an on line environment. Charlottesville, VA: Association for the Advancement of Computing in Education (AACE).

[15] Mohsenpoor M, Hejazi E, Kiamanesh A (2006). The role of selfefficacy, goal achievement and persistence in mathematic course of high-school students at Tehran, journal of educational innovation; 5(16): 9-35 [In Persian].

[16] Pintrich, P. R., \& De Groot, E. V. (1990). Motivational and self-regulated learning components of classroom academic performance. Journal of Educational Psychology, 82, 33-40.

[17] Rastegar A. (2006). The Relationship of Intelligence Beliefs and Academic Achievement: The Mediating Role of Achievement Goals and Academic Engagement, MA Thesis. Tehran: Tehran University.

[18] Schunk, D. H., Pintrich, P. R., \& Meece, J. L. (2008). Motivation in education: theory, research, and applications (3rd ed.). Upper Saddle River, N.J.: Pearson/Merrill Prentice Hall.

[19] Stipec, D., \& Gralinski, G. H. (1996). Children’s belief about intelligence \& school performance. Journal of Educational Psychology. 88, 397-407.

[20] Zimmerman, B. J. (2002). Becoming a self-regulated learner: An overview. Theory into Practice, 41(2), 64-72.

[21] Zimmerman, B.J. \& Martinez-Pons, M. (1990). Student differences in self-regulated learning: Relating grade, sex \& giftedness to self-efficacy \& strategy use. Journal of Educational Psychology, 82(1), 51-59.

\section{Appendix}

\section{Questionnaire on Self-Regulation}

1. I have a hard time controlling my temper.

2. I get so frustrated I feel ready to explode.

3. I get upset easily.

4. I am afraid I will lose control over my feelings.

5. I slam doors when I am mad.

6. I develop a plan for all my important goals.

7. I think about the future consequences of my actions.

8. Once I have a goal, I make a plan to reach it.

9. I get distracted by little things.

10. As soon as I see things that are not working, I do something about it.

11. I get fidgety after a few minutes if I am supposed to sit still.

12. I have a hard time sitting still during important tasks.

13. I find that I bounce my legs or wiggle with objects.

\section{Questionnaire on achievement goal}

1. I would feel good if I was the only one who could answer the teacher's questions in class.

2. I would like to show my teachers that I'm smarter than the other kids.

3. I would feel successful in school if I did better than the other students in my classes.

4. I'd like to show my parents that I'm smarter than the other kids in my classes.

5. I wish we had school work that would let me show I'm smart.

6. Understanding the work in school is more important to me than the grade I get.

7. I like school work that I'll learn from even if I make a lot of mistakes.

8. The main reason I do my work in school is because I like to learn.

9. I like school work the best when it really makes me think.

10. I feel most successful in school when I learn something I didn't know before.

11. It doesn't matter to me if other students do better than I do, as long as I am learning. 